\title{
Experimental Study on the Dynamic Performance of Water-Lubricated Rubber Bearings with Local Contact
}

\author{
Wu Ouyang $\left(\mathbb{D},{ }^{1}\right.$ Xuebing Zhang, ${ }^{2}$ Yong Jin, ${ }^{3}$ and Xiaoyang Yuan ${ }^{4}$ \\ ${ }^{1}$ Reliability Engineering Institute, Key Laboratory of Marine Power Engineering \& Technology, Ministry of Transport, \\ School of Energy and Power Engineering, Wuhan University of Technology, Wuhan, China \\ ${ }^{2}$ Wuhan Second Ship Design and Research Institute, Wuhan, China \\ ${ }^{3}$ School of Energy and Power Engineering, Wuhan University of Technology, Wuhan, China \\ ${ }^{4}$ Key Laboratory of Education Ministry for Modern Design and Rotor-Bearing System, Xian Jiaotong University, Xian, China
}

Correspondence should be addressed to Wu Ouyang; ouyangw@whut.edu.cn

Received 13 September 2017; Revised 13 December 2017; Accepted 25 December 2017; Published 30 January 2018

Academic Editor: Matteo Aureli

Copyright (C) $2018 \mathrm{Wu}$ Ouyang et al. This is an open access article distributed under the Creative Commons Attribution License, which permits unrestricted use, distribution, and reproduction in any medium, provided the original work is properly cited.

Accurate dynamic characteristic coefficients of water-lubricated rubber bearings are necessary to research vibration of ship propulsion system. Due to mixed lubrication state of water-lubricated rubber bearings, normal test rig and identification method are not applicable. This paper establishes a test rig to simulate shaft misalignment and proposes an identification method for waterlubricated rubber bearings, which utilizes rotor unbalanced motion to produce self-excited force rather than artificial excitation. Dynamic performance tests under different conditions are operated. The results show that when rotational speed is less than $700 \mathrm{r} / \mathrm{min}$, even if specific pressure is $0.05 \mathrm{MPa}$, it is difficult to form complete water film for the rubber bearing which was investigated, and contact friction and collision of the shaft and bearing are frequent. In the mixed lubrication, water film, rubber, and contact jointly determine dynamic characteristics of water-lubricated rubber bearings. The contact condition has a significant effect on the bearing stiffness, and water film friction damping has a significant effect on bearing damping. As for the particular investigated bearing, when rotational speed is in the range of $400 \sim 700 \mathrm{r} / \mathrm{min}$ and specific pressure is in the range of $0.03 \sim 0.07 \mathrm{MPa}$, bearing stiffness is in the range of $5.6 \sim 10.06 \mathrm{~N} / \mu \mathrm{m}$ and bearing damping is in the range of $1.25 \sim 2.02 \mathrm{Ns} / \mu \mathrm{m}$.

\section{Introduction}

Increased level of environmental awareness and energy saving objective have promoted a growing interest in environmentally friendly technologies in recent years. Waterlubricated bearings have good wear resistance, stable chemical property, and environment friendliness which are being used in vessel propulsion system, hydropower, water pumps, and other industrial sectors. Water-lubricated rubber bearings are used to support the propeller shaft, and researches show that propulsion rotor system is the most important factor of vessel noise $[1,2]$. Dynamic characteristics of waterlubricated rubber bearings affect the dynamic behavior of propeller rotor system, which directly determine operation state and quality of propulsion system $[3,4]$. Obtaining dynamic characteristic coefficients of rubber bearings is meaningful to assess stability and fault diagnosis of the rotorbearing system $[5,6]$.

Pertinent literatures report many identification methods of bearing dynamic characteristic coefficients, which can be divided into stable excitation method $[7,8]$ and transient excitation method $[9,10]$. The former mainly includes compound excitation method, single-frequency twice excitation method, and multifrequency excitation method. And the later mainly includes wide-band excitation method. Parkins [11] used compound excitation method and obtained bearing's linear damping coefficients in horizontal and vertical directions. Reddy et al. [12] used the single-frequency twice excitation method to measure dynamic characteristic coefficients of tilting-pad journal bearings, which is only $10 \%$ different from the theoretical value. The exciting force of wide-band excitation method is transient signal, whose 


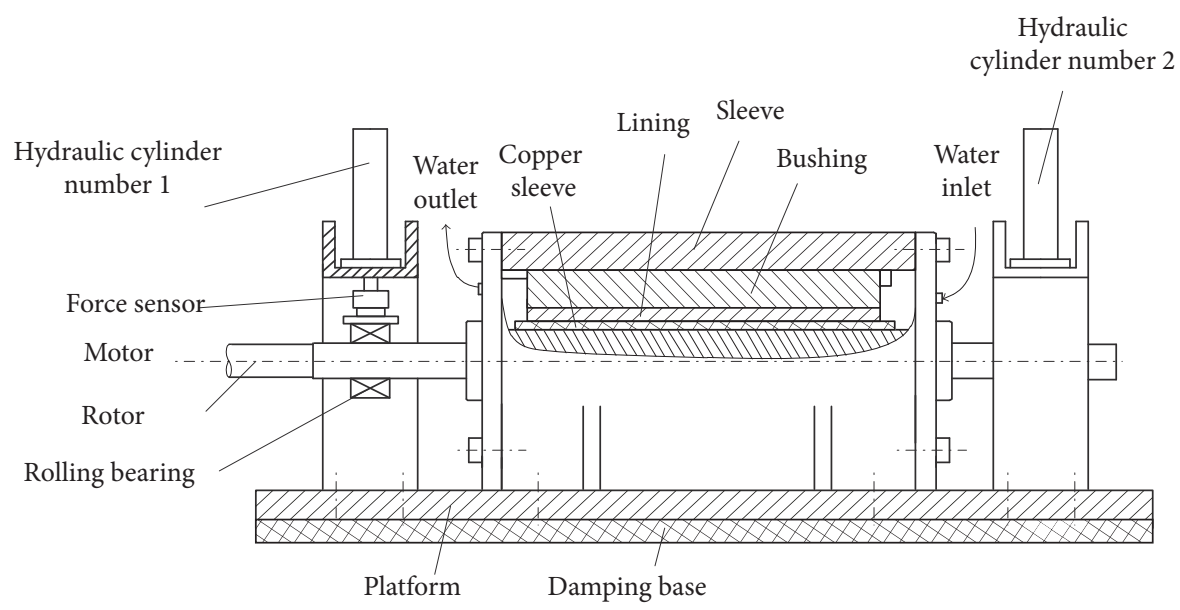

Figure 1: Schematic diagram of the test rig.

response energy is scattered and the signal-to-noise ratio is low. Wang [13] used the noncontact harmonic excitation method and the additional unbalance excitation method to measure a high-speed water-lubricated hybrid bearing. Most of these dynamic excitation methods are based on specialized bearing test rigs, which can be divided into "positive" [13] and "inverted" [14]. In the former case, test bearing is suspended on shaft, and test bearing response is from direct exciting force, while in the latter case, test bearing is fixed in bearing seat and exciting force working on the shaft is passed to test bearing. These test methods and test rigs are mostly for oil-lubricated bearings and less for water-lubricated rubber bearings.

Due to the particularity of material and application conditions, it is difficult to operate dynamic experiment of water-lubricated rubber bearings. Firstly, rubber is very soft, its elastic modulus is only $0.04 \%$ of that of steel, and rubber bearing lining surface is prone to obvious deformation under stress [15]. Moreover, vessel propeller hangs on one end of the propeller shaft, causing bend of propeller shaft [16]. With shaft misalignment, there is always mixed lubrication of dry friction, boundary lubrication, and film lubrication on the interface of water-lubricated rubber bearings [17]. By this time, dynamic characteristics of rubber bearings are very complex and affected by factors such as extruded water film, rubber property, and contact condition $[18,19]$. It is difficult for "inverted" bearing test rig to simulate this mixed lubrication state, which leads to difficulty in implementing dynamic characteristic test method based on the test rig [20]. The "positive" bearing test bench can simulate the shaft misalignment, but it is difficult to use artificial excitation on the tilting shaft.

This work aims to propose identification method of dynamic characteristics coefficients of water-lubricated rubber bearing with local contact and obtain dynamic performance rules. Section 2 introduces the experimental apparatus. The test scheme and procedure are proposed in Section 3. Section 4 gives the results and discussion. Finally, conclusion is given in Section 5 .

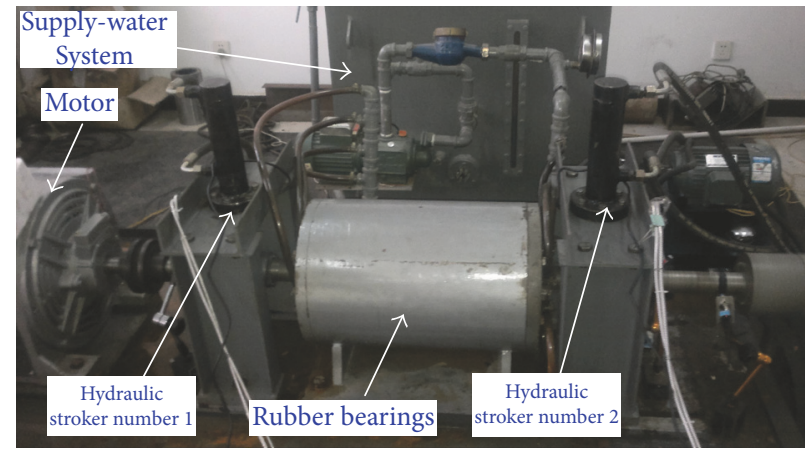

FIgURE 2: Photograph of the test rig.

\section{Experimental Apparatus}

2.1. Test Rig. In order to simulate shaft misalignment of water-lubricated rubber bearings' actual operation, "positive" bearing test rig is designed as shown in Figures 1 and 2. The test rig includes variable frequency motor, rotor-bearing system, hydraulic loading system, and water lubrication system. The measure system mainly includes sensors, signal transmitter, data acquisition card, and identification software of dynamic characteristic coefficients. Test bearing is fixed on the bearing seat, and support shaft. There are hydraulic loading devices on both sides of test bearing. Two deep groove ball bearings are used for applying load which get lubricated by grease, and a force sensor is mounted on the top of load pole. When two loading forces are not equal, the shaft will tilt. The working conditions of test rig are rotational speed of $0 \sim 1000 \mathrm{r} / \mathrm{min}$, loading force of $0 \sim 1 \mathrm{t}$, and water pressure of $0.1 \sim 0.6 \mathrm{MPa}$. Strain gauge drawing force and compression force sensors are used, PLD204KM. Rated capacity $(E \max )$ is $1000 \mathrm{~kg}$, rated output is $2.0 \pm 10 \% \mathrm{mV} / \mathrm{V}$, and ultimate overload is $200 \%$ FS.

2.2. Test Bearings. The structure of test bearings is shown in Figure 3, which is composed of bushing and complete rubber 


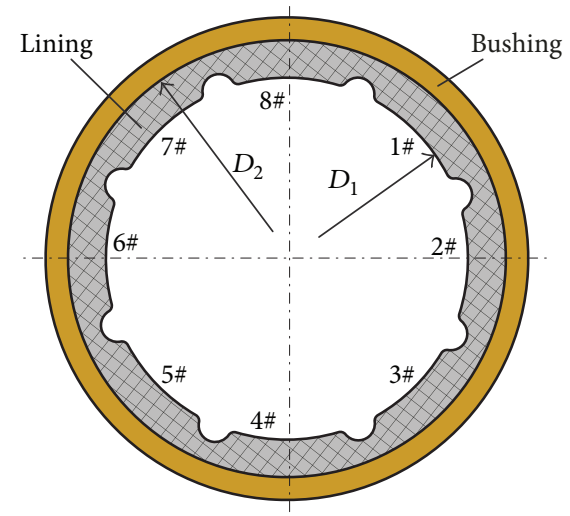

FIGURE 3: Schematic diagram of rubber bearings.

TABLE 1: Physical parameters of the rubber bearing.

\begin{tabular}{lc}
\hline Parameters & Values \\
\hline Inner diameter $D_{1}(\mathrm{~mm})$ & 100.4 \\
Outer diameter $D_{2}(\mathrm{~mm})$ & 121 \\
Length-diameter ratio & 4.23 \\
Relative clearance $(\%)$ & 4 \\
Groove number & 8 \\
Groove angle $\left({ }^{\circ}\right)$ & 8 \\
Groove depth $(\mathrm{mm})$ & 5 \\
Rotational speed $(\mathrm{r} / \mathrm{min})$ & $100 \sim 1000$ \\
Specific pressure $(\mathrm{MPa})$ & $0 \sim 0.1$ \\
Water feed temperature $\left({ }^{\circ} \mathrm{C}\right)$ & 25 \\
\hline
\end{tabular}

lining. The basic parameters are shown in Table 1. There are 8 pads in the bearing, shaft diameter is $100,00 \mathrm{~mm}$, and diameter clearance is $0.4 \mathrm{~mm}$. The lining material is nitrilebutadiene rubber (NBR), and the rubber's Shore A hardness is 76. Surface roughness of the rubber is Ra 1.6. When installing the bearing, a pad is at the bottom (4\#). During testing, water is supplied at one end of bearings and outflows from the other end.

\section{The Test Scheme and Procedure}

As shown in Figure 1, test bearings are fixed to the bearing seat, and it is difficult to actively excite test bearings. In this paper, an identification method of dynamic specific coefficients based on rotor self-excited is proposed, which does not need to apply external exciting force but uses rotor self-excited force and rotor vibration data to identify stiffness and damping coefficients of water-lubricated bearings. As shown in Figure 4, at certain critical speed, the load bar loads on the rotor through rolling bearings. The force sensor set between the load bar and the rolling bearing will measure a composite force superimposed by the static force and dynamic force. The static force is the hydraulic loading force, and the dynamic force is self-excited force generated by shaft due to unbalanced operation. The DC component of the signal is the static force, which can be obtained by fast Fourier transform (FFT). Remove the DC component and get the dynamic force.

The mechanical model of test bearing system is simplified as shown in Figure 5. The test bearing is assumed to two sections to support the shaft, and the dynamic equation of one section is

$$
m_{1 i} \ddot{Y}_{d}+c_{b i} \dot{Y}_{d i}+k_{b i} Y_{d i}+k_{0 i} Y_{d i}=F_{d i}
$$

where $i$ represents number of two segments of bearings, 1 is the near motor part, and 2 is far motor part; $m_{1 i}$ is the vibration quality, equaling the sum of $m_{11}$ and $m_{12}$, which are two parts of shaft weight. $k_{0 i}$ and $k_{b i}$ are parallel. When $k_{0 i}$ is less than $10 \%$ of $k_{b i}, k_{0 i}$ can be omitted.

The generation mechanism of $k_{0 i}$ will be analyzed as follows. Figure 6 is the mechanical model for connection part, where $m_{0}$ is vibration quality of connection part, including the load pole, rolling bearing, and force sensors. The following equation can be established:

$$
k_{0 i}=\frac{k_{g i} k_{y i}}{k_{g i}+k_{y i}}-\frac{k_{g i}^{2} m_{0}}{\left(k_{g i}+k_{y i}\right)^{2}} \omega^{2} .
$$

$k_{0 i}$ can be reduced by reducing $k_{g i}$. Choose small stiffness of butterfly springs between force sensors and hydraulic pole to reduce $k_{0 i}$. After stacking, $k_{0 i}$ is about $0.26 \mathrm{~N} / \mu \mathrm{m}$, about $2.9 \%$ of bearing stiffness $9 \mathrm{~N} / \mu \mathrm{m}$. Then, $k_{0 i} Y_{d i}$ in (1) can also be omitted.

Then compute Fourier transform to the simplified equation:

$$
\left(k_{b i}-m_{1 i} \omega^{2}+j \omega c_{b i}\right) Y_{d i}(\omega)=F_{d i}(\omega) .
$$

Equation (3) is the dynamic characteristics test equation of the rubber bearing. The initial phase angle of force is set as $\varphi_{1 i}$; then the excitation force and displacement are

$$
\begin{aligned}
& \mathbf{F}_{d i}=F_{d i} e^{j\left(\omega t+\varphi_{1 i}\right)}, \\
& \mathbf{Y}_{d i}=Y_{d i} e^{j\left(\omega t+\varphi_{2 i}\right)} .
\end{aligned}
$$

The displacement impedance method [20] is used to identify dynamic characteristic coefficients of the rubber bearing. The displacement impedance is

$$
\mathbf{Z}_{i}=\frac{\mathbf{F}_{d i}}{\mathbf{Y}_{d i}}=\frac{F_{d i}}{Y_{d i}}\left[\cos \left(\varphi_{1 i}-\varphi_{2 i}\right)+j \sin \left(\varphi_{1 i}-\varphi_{2 i}\right)\right] .
$$

Then dynamic characteristic coefficients of one part of bearing are

$$
\begin{aligned}
k_{b i} & =\operatorname{Re}\left(\mathbf{Z}_{i}\right)+\omega^{2} m_{1 i}, \\
c_{b i} & =\frac{\operatorname{Re}\left(\mathbf{Z}_{i}\right)}{\omega} .
\end{aligned}
$$

Due to eccentricity installation of rotor and coupling and some weak nonlinear factors, there surely are higher harmonics and subharmonic components that are not synchronized with the unbalanced excitation frequency of rotor 


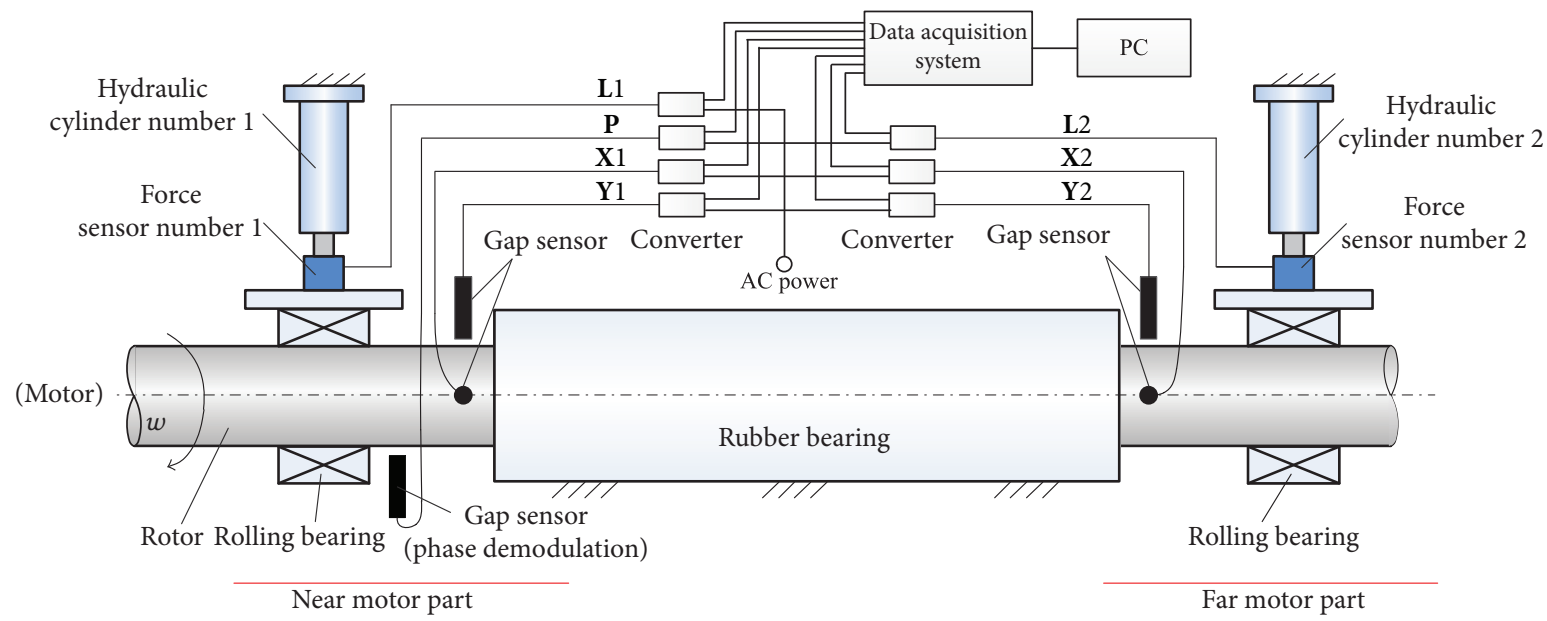

FIGURE 4: Identification scheme of dynamic characteristic coefficients of water-lubricated rubber bearings.

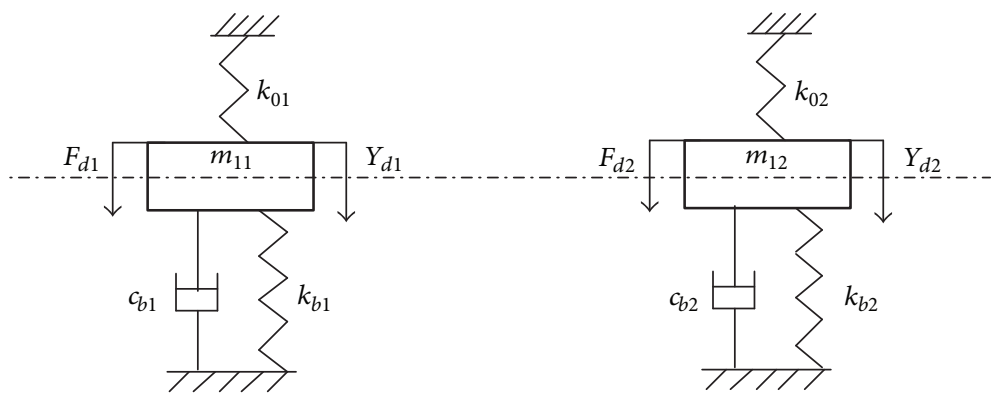

Figure 5: Mechanical model of bearing system.

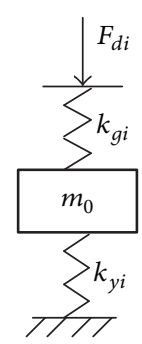

Figure 6: Mechanical model of connection part.

in signals. But only fundamental wave information corresponding to test equation can be extracted when processing signals; dynamic force and displacement can be obtained by fundamental wave detection and tracking method [13].

Stiffness and damping coefficients of the bearing are obtained by the superposition of two sections. Superposition of parallel stiffness can be added. Damping superposition mechanism is very complex, and addition is used in this paper. So equivalent bearing dynamic characteristic coefficients are

$$
\begin{aligned}
& k_{b}=k_{b 1}+k_{b 2}, \\
& c_{b}=c_{b 1}+c_{b 2} .
\end{aligned}
$$

TABLE 2: Test parameters.

\begin{tabular}{lcc}
\hline $\begin{array}{l}\text { Specific pressure } \\
(\mathrm{MPa})\end{array}$ & $\begin{array}{c}\text { Rotational speed } \\
(\mathrm{r} / \mathrm{min})\end{array}$ & Running time $(\mathrm{h})$ \\
\hline 0.03 & & 1 \\
0.05 & & 1 \\
0.06 & $400 / 500 / 600 / 700$ & 1 \\
0.07 & & 1 \\
0.1 & & 1 \\
\hline
\end{tabular}

This identification method is simple to implement, and it has application prospect for dynamic characteristic test in field unit. For example, sensor dynamic load can be installed on the back of bearings, and joint vibration data can identify dynamic characteristic coefficients of bearings.

The test parameters include rotational speed, specific pressure, and running time. As shown in Table 2, at each specific pressure, there are four kinds of rotational speeds. Each working condition lasted for 25 minutes, and rotor operation is stable at this time. Then, Force and vibration data was recorded.

\section{Experimental Results and Discussion}

Before identifying dynamic characteristic, it is necessary to determine bearing lubrication condition according to 


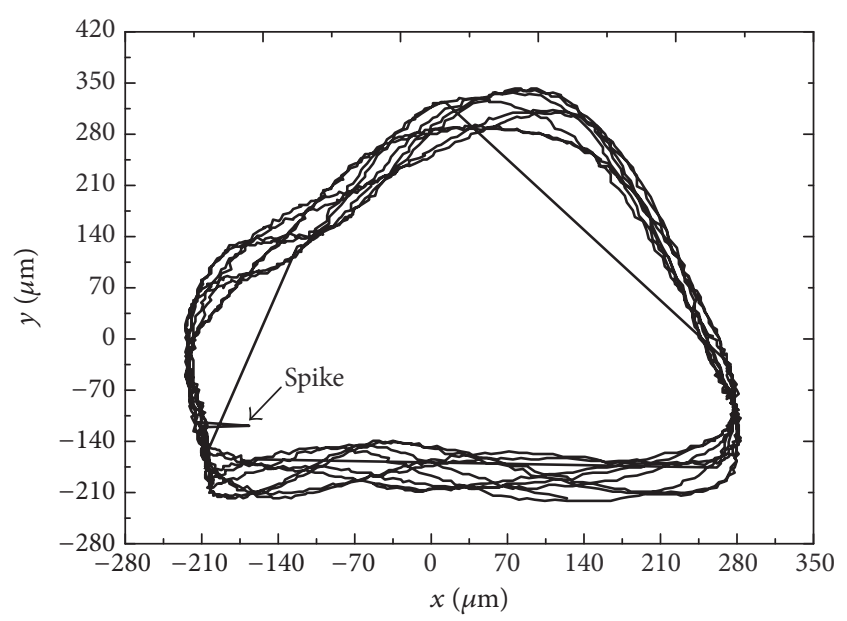

(a) $0 \mathrm{MPa}$, near motor part

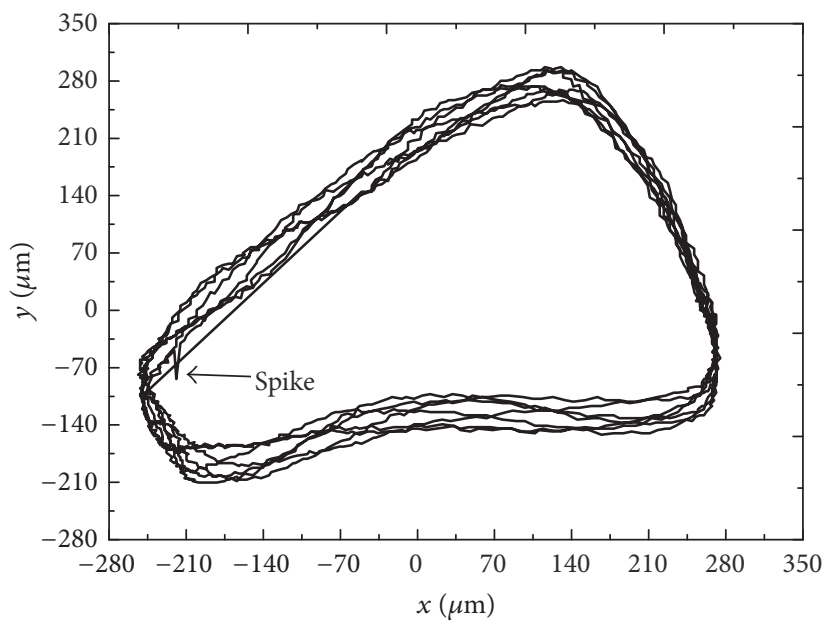

(c) $0.05 \mathrm{MPa}$, near motor part

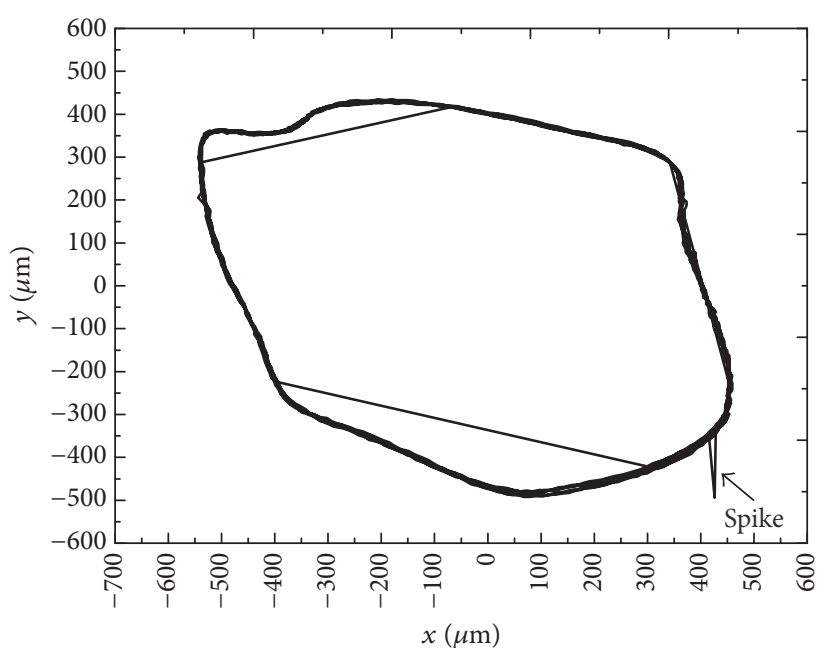

(b) $0 \mathrm{MPa}$, far motor part

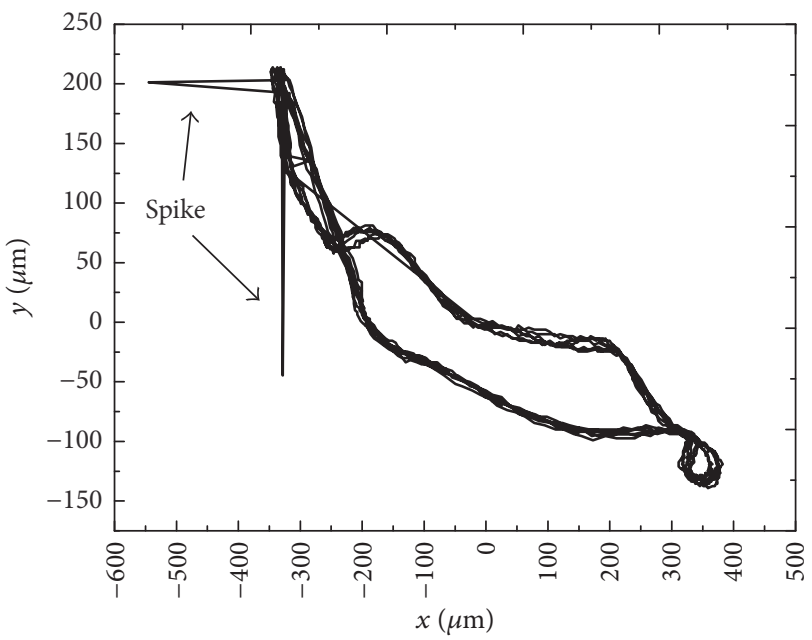

(d) $0.05 \mathrm{MPa}$, far motor part

FiguRE 7: Shaft orbit in $400 \mathrm{r} / \mathrm{min}$.

vibration phenomenon. Rotational speed of $400 \mathrm{r} / \mathrm{min}$ and linear velocity of about $2.1 \mathrm{~m} / \mathrm{s}$ are considered as low speed. Orbit with and without load is shown in Figure 7. When there is no load, the orbit is approximately elliptical, indicating that the rotor is unbalanced. The orbits of near and far motor parts show spikes and saltation lines. The saltation is very obvious. It is analyzed that it is not caused by the test error but may be caused by changes of rotor position when the rotor collides with bearings. As shown in Figure 7(b), the track's maximum amplitude of orbit reaches $400 \mu \mathrm{m}$ in far motor part. It is similar to the diameter gap between rotor and bearing, which shows that rotor and bearing in far motor pad are in the state of continuous contact. The movement amplitude of near motor part is less than $280 \mu \mathrm{m}$, which indicates that this part is in the state of dynamic lubrication and occasional collision. In conclusion, the bearing is in mixed lubrication state where there is local contact at low speed.

Figures $7(\mathrm{c})$ and $7(\mathrm{~d})$ are orbits in rotational speed of $400 \mathrm{r} / \mathrm{min}$ and specific pressure of $0.05 \mathrm{MPa}$ when rotors are loaded on two sides or bearing. Compared with no load, the movement amplitude of rotor is obviously reduced: for the far motor part, it is less than $280 \mu \mathrm{m}$. For the near motor part, the movement amplitude of vertical direction is less than $220 \mu \mathrm{m}$. Shaft orbit is 8-shaped and banana shaped for the far motor part, indicating that the rotor is unbalanced and misaligned. There are still spikes on shaft orbits and especially some large spikes appear in the horizontal direction of far orbit, which is caused by rub and impact due to no static force constraints.

In order to further explain the phenomenon, Figure 8 shows the rotor time domain waveforms. When the rotor is not loaded, far motor part's movement amplitude is greater than that of the near motor part. After loading, the former is less than the later due to static force of vertical direction. Periodic small peak has the same frequency with fundamental frequency, which indicates that there are periodic collisions in this direction.

Figure 9 shows shaft orbits at the rotational speed $700 \mathrm{r} / \mathrm{min}$ with and without load and line speed is about 


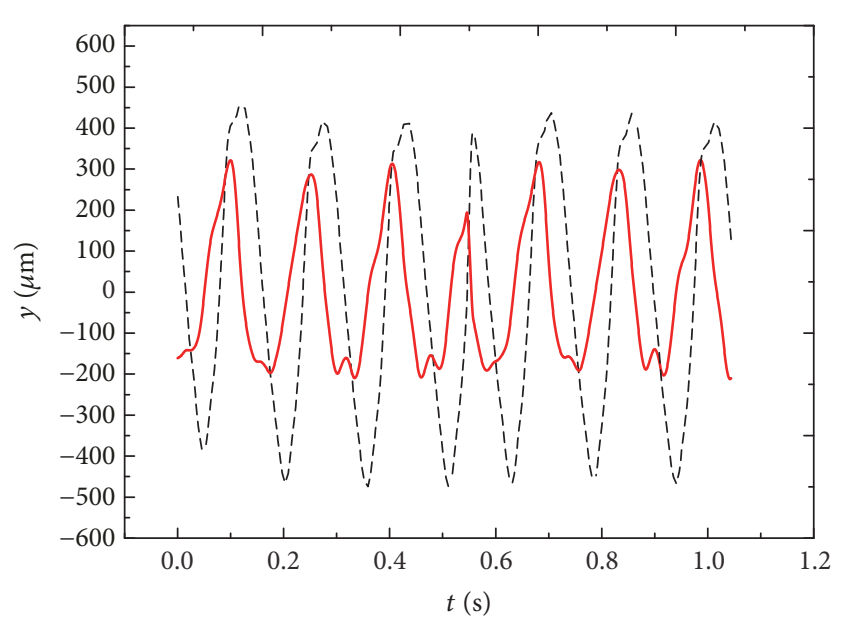

--- Far motor part — Near motor part

(a) $0 \mathrm{MPa}$

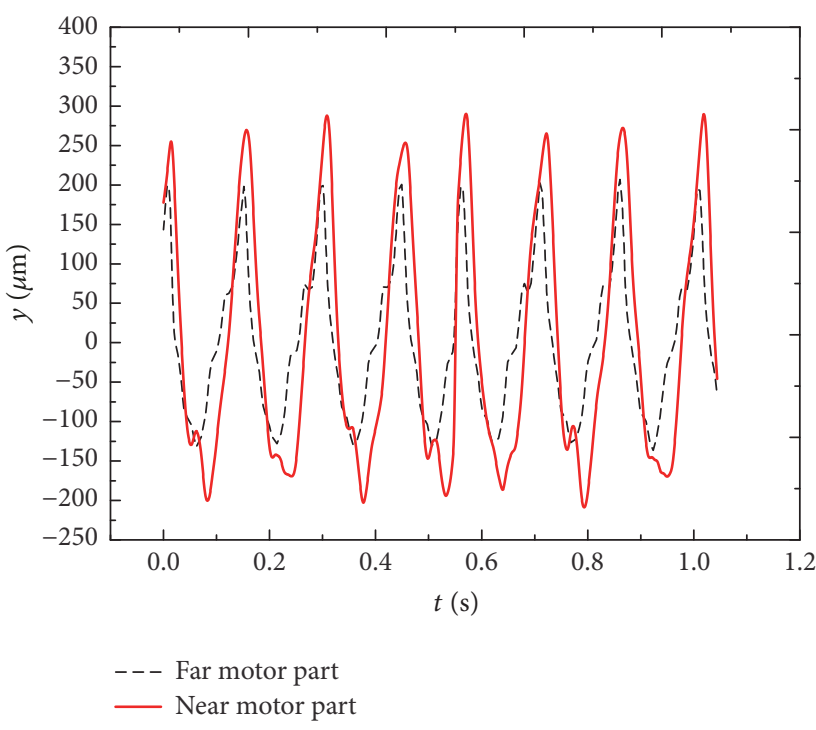

(b) $0.05 \mathrm{MP}$

FIgURE 8: The rotor time domain waveforms in vertical direction, $400 \mathrm{r} / \mathrm{min}$.

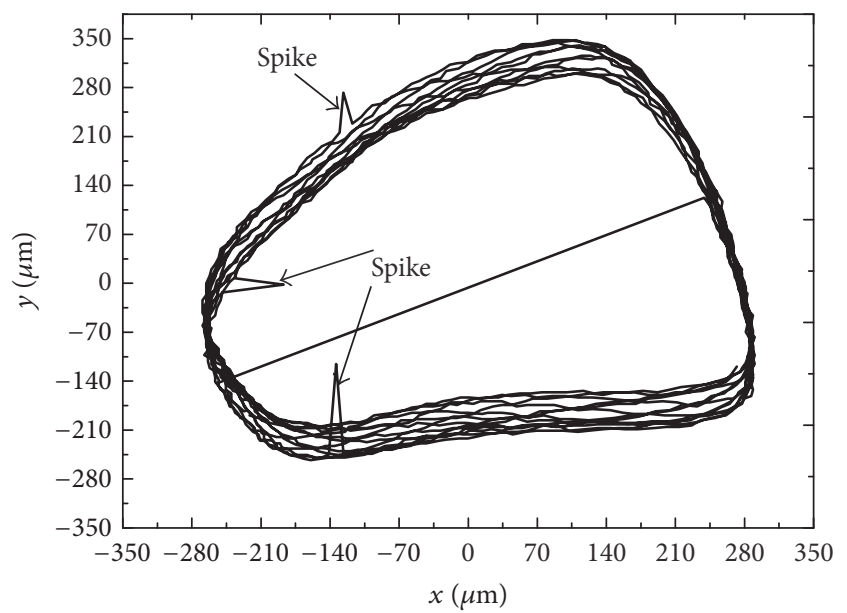

(a) $0 \mathrm{MPa}$, near motor part

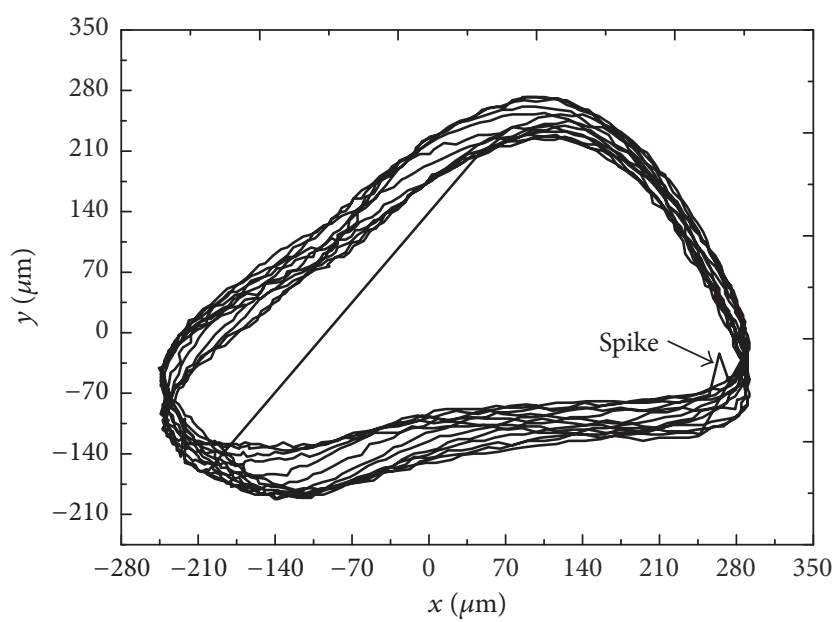

(c) $0.05 \mathrm{MPa}$, near motor part

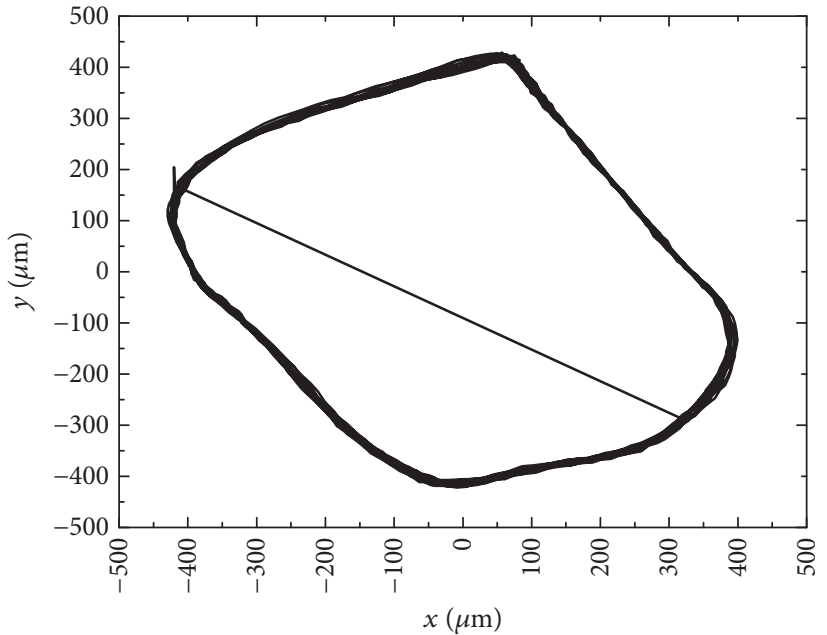

(b) $0 \mathrm{MPa}$, far motor part

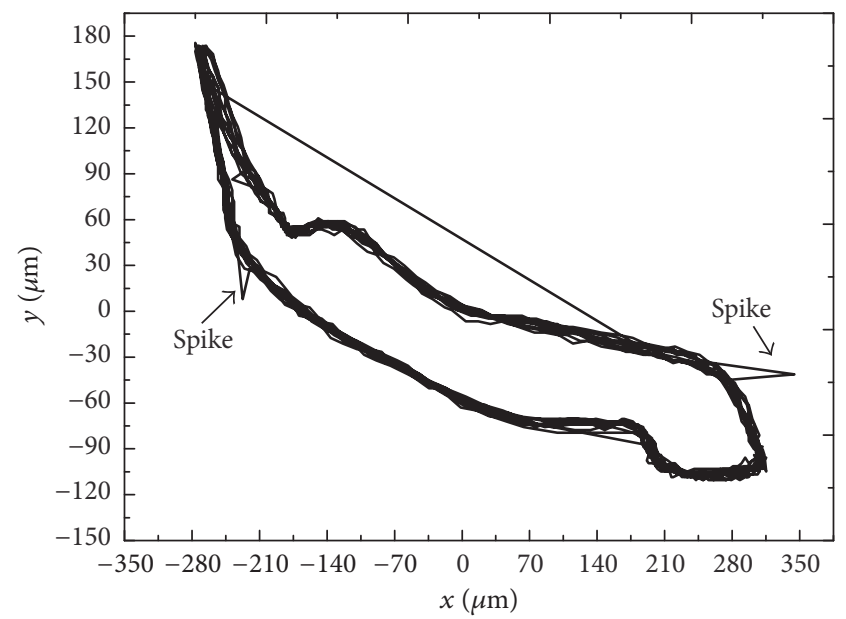

(d) $0.05 \mathrm{MPa}$, far motor part

FIGURE 9: Shaft orbit in $700 \mathrm{r} / \mathrm{min}$. 


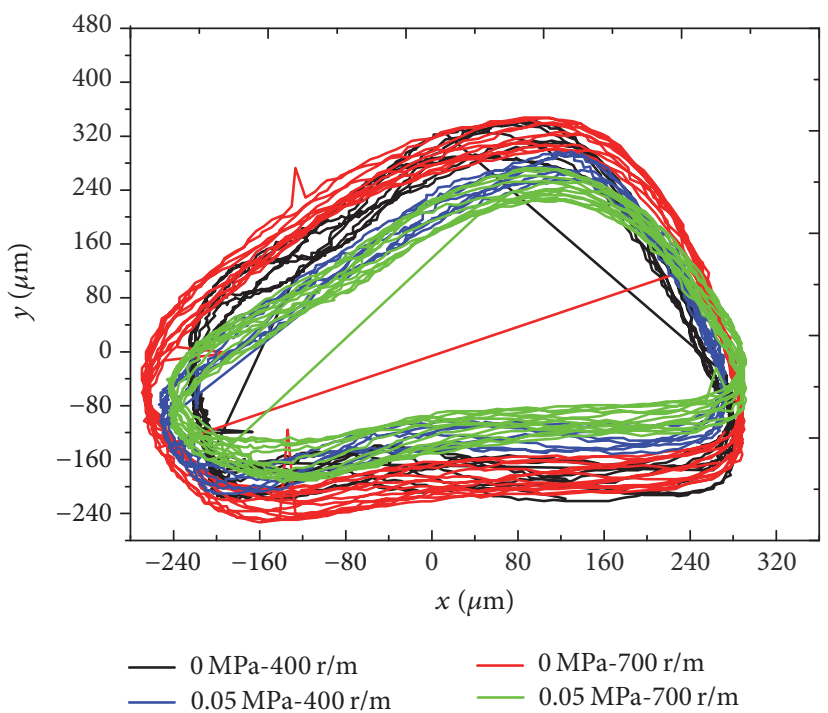

(a) Near motor part

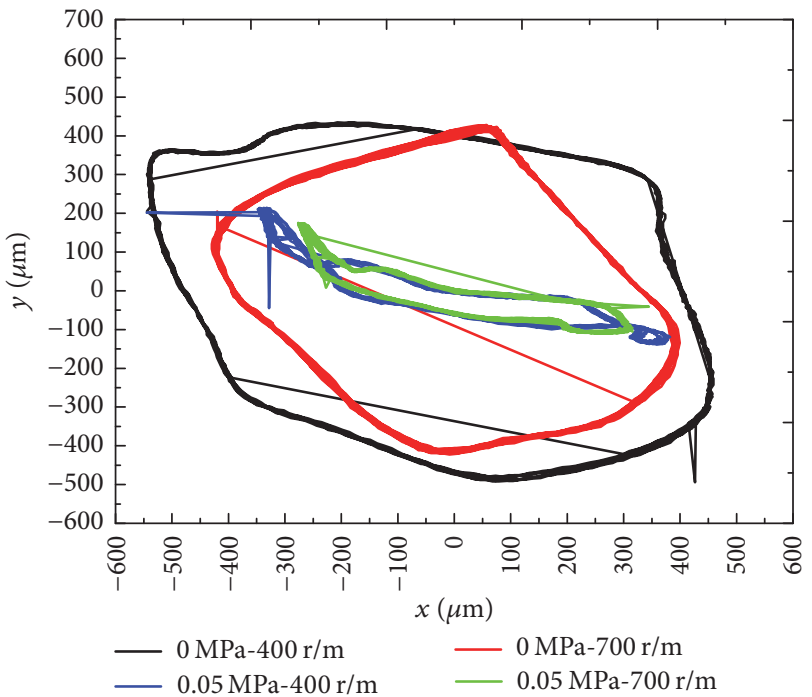

(b) Far motor part

FIGURE 10: Orbits with various loads and speeds.

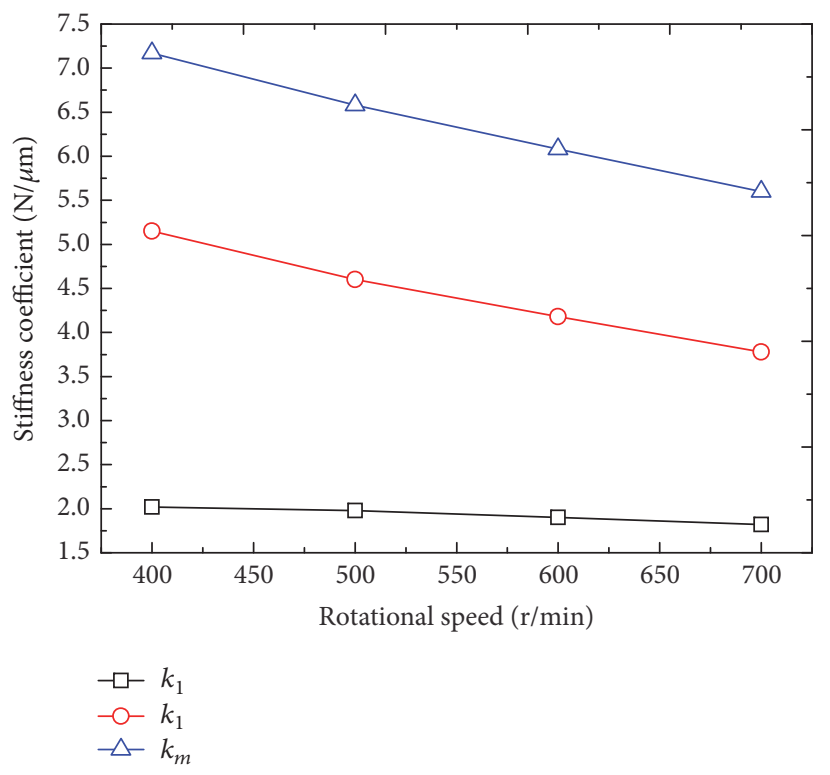

(a) Specific pressure $0.03 \mathrm{MPa}$

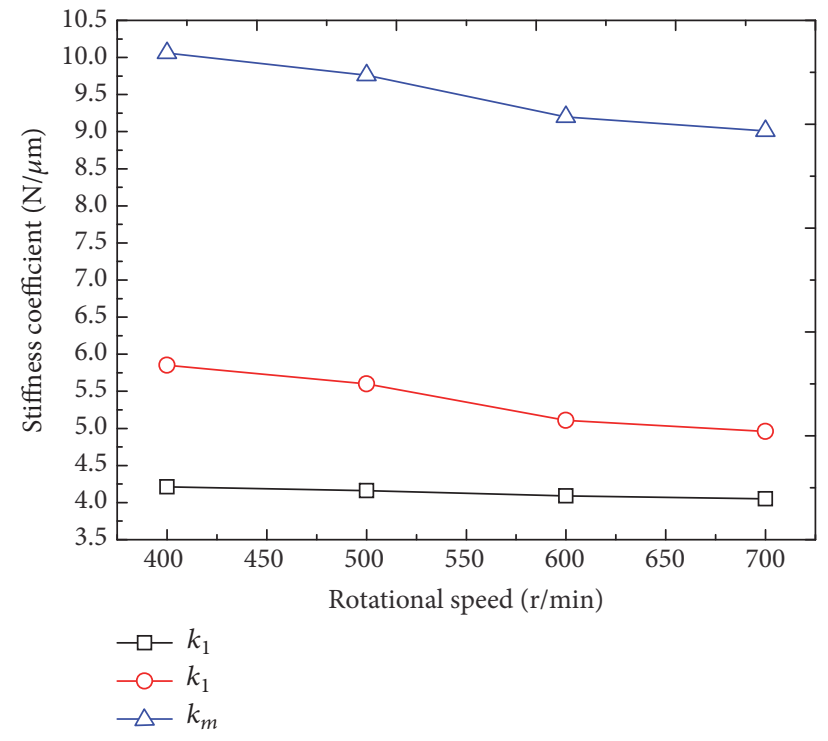

(b) Specific pressure $0.07 \mathrm{MPa}$

Figure 11: Stiffness coefficient identified at different loads and speeds.

$3.7 \mathrm{~m} / \mathrm{s}$. The basic rules of shaft orbit at $700 \mathrm{r} / \mathrm{min}$ are similar to those at $400 \mathrm{r} / \mathrm{min}$, but there are more spikes in the horizontal direction of near motor part at $700 \mathrm{r} / \mathrm{min}$, and there is a horizontal line in orbits of two parts, which may be caused by saltation of shaft due to collisions, and this saltation line also exists when loading. At the speed of $700 \mathrm{r} / \mathrm{min}$, orbit of far motor part is banana shaped rather than 8-shaped, and increasing speed is conducive to weaken misalignment.

Adding different orbits into one figure, Figure 10 shows how orbits migrate, and change size with the change of working condition. As for near motor part, with increasing speed or load, orbit has a decreasing trend. However, it has a small change due to restricting from coupling. As for far motor part, the size of orbit significantly reduces with the increase of speed or load, and its shape becomes more and more elongated.

Figure 11 shows stiffness and damping coefficients identified at different loads and speeds. As shown in Figure 11(a), when the specific pressure is $0.03 \mathrm{MPa}$, stiffness coefficients at both parts of rubber bearing decrease while increasing rotational speed. For example, equivalent stiffness of bearing at $400 \mathrm{r} / \mathrm{min}$ is $7.17 \mathrm{~N} / \mu \mathrm{m}$, which is 2.5 times more than that at $700 \mathrm{r} / \mathrm{min}$. In addition, the far part stiffness is significantly larger than the near part stiffness. Because motion amplitude 


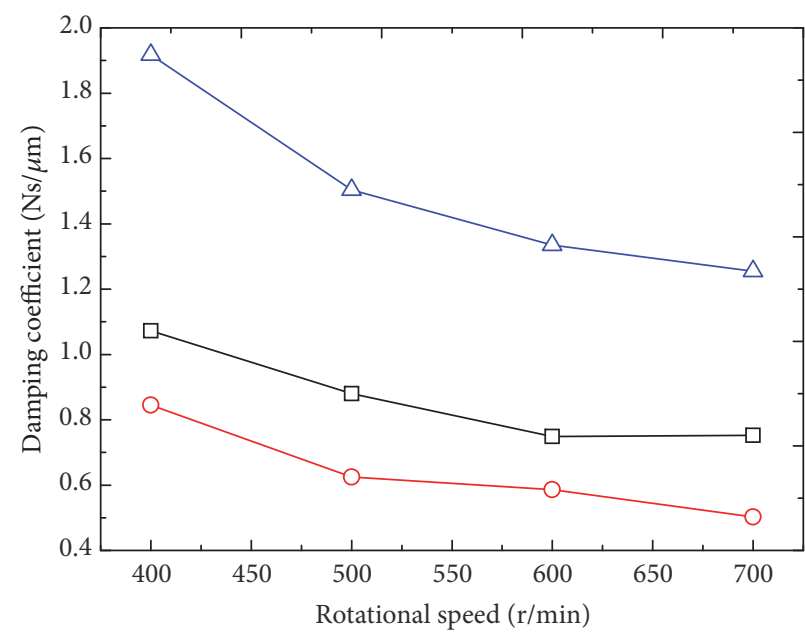

$$
\begin{aligned}
& -\square-c_{1} \\
& -\bigcirc-c_{1}
\end{aligned}
$$$$
\triangle c_{m}
$$

(a) Specific pressure $0.05 \mathrm{MPa}$

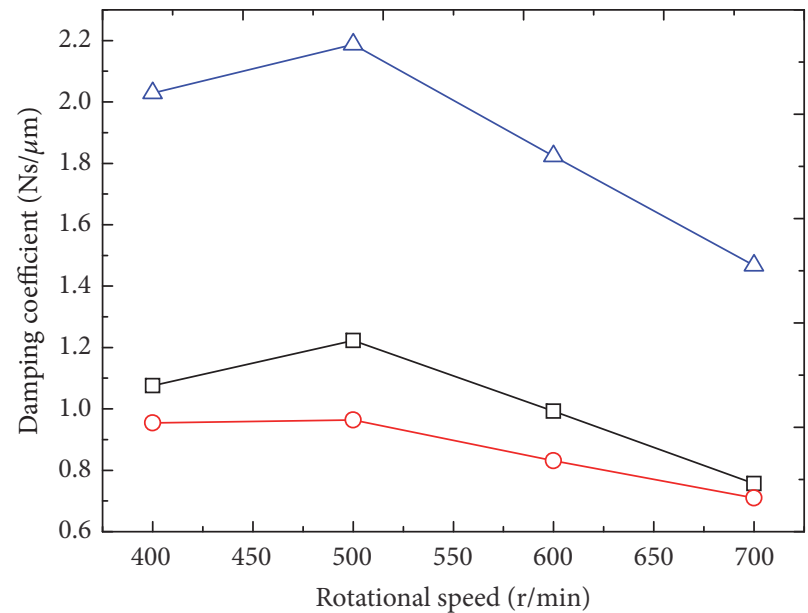

$$
\begin{aligned}
& -\square-c_{1} \\
& -\circ-c_{2} \\
& -c_{m}
\end{aligned}
$$

(b) Specific pressure $0.06 \mathrm{MPa}$

FIgURE 12: Damping coefficient identified at different loads and speeds.

of fast part is larger than that of near part, times and areas of contacting between shaft and bearing are larger, and squeezing effect of shaft is more pronounced on rubber. With increasing speed, this difference becomes smaller. The reason is when the speed becomes higher contact situation on both parts becomes more and more similar. From this point of view, the contact situation has a significant effect on bearing stiffness. As shown in Figure 11(b), when the specific pressure is $0.07 \mathrm{MPa}$, the rule of bearing stiffness is similar to the condition of $0.03 \mathrm{MPa}$, but stiffness increases obviously. For example, when rotational speed is $400 \mathrm{r} / \mathrm{min}$ and specific pressure is $0.07 \mathrm{MPa}$, the equivalent stiffness of bearing is $10.06 \mathrm{~N} / \mu \mathrm{m}$, which is 1.4 times of that at $0.03 \mathrm{MPa}$. In condition of $400 \sim 700 \mathrm{r} / \mathrm{min}$ rotational speed and $0.03 \sim$ $0.07 \mathrm{MPa}$ specific pressure, bearing stiffness is in the range of $5.6 \sim 10.06 \mathrm{~N} / \mu \mathrm{m}$.

As shown in Figure 12(a), when the specific pressure is $0.05 \mathrm{MPa}$, damping coefficients at both pads of bearings increase substantially with increasing of rotational speed. For example, equivalent damping of bearing at $400 \mathrm{r} / \mathrm{min}$ is $1.72 \mathrm{Ns} / \mu \mathrm{m}$, and it is 1.5 times that at $700 \mathrm{r} / \mathrm{min}$. When rotational speed is $600 \mathrm{r} / \mathrm{min}$, the damping of far motor part fluctuates slightly. In addition, unlike stiffness changing, the damping of near motor part is slightly larger than that of far part. Bearing damping is mainly composed of water film friction damping, rubber material damping, and contact damping. The times and area of near part contact are smaller than those of far part; that is, water film of near part is better than that of far part. So water film friction damping of near part is greater than that of far part. Although the far contact damping may be greater than the near contact damping, the near bearing damping is greater than that of far part. From this point of view, water film friction damping impacts more significantly on bearing damping than other factors.
As shown in Figure 12(b), damping coefficients at both parts decrease substantially with the increasing of rotational speed. However, at $600 \mathrm{r} / \mathrm{min}$, damping fluctuates at both parts. This fluctuation may be caused by sharp collisions between shaft and bearing. In addition, the greater the load is, the greater the bearing damping becomes. For example, when rotational speed is $400 \mathrm{r} / \mathrm{min}$ and specific pressure is $0.06 \mathrm{MPa}$, equivalent damping of bearing is $2.03 \mathrm{Ns} / \mu \mathrm{m}$, which is 1.2 times that at $0.05 \mathrm{MPa}$. In condition of $400 \sim 700 \mathrm{r} / \mathrm{min}$ rotational speed and $0.03 \sim 0.07 \mathrm{MPa}$ specific pressure, the bearing damping is in the range of $1.25 \sim 2.02 \mathrm{Ns} / \mu \mathrm{m}$.

As mentioned, there is the mixed lubrication on interface of water-lubricated rubber bearings. It is hard to precisely measure the size and location of contact area, so the contact state has to be simplified. Divide the loading area into one contact region $\Omega_{t}$ and one lubricating region $\Omega_{l}$ [20], as shown in Figure 13.

Bearing stiffness $k_{b}$ is composed of contact region stiffness $k_{t}$ and lubricating region stiffness $k_{l}$; they are solved, respectively, and composite $k_{b}$ is obtained. The similar method can be used to get bearing damping $c_{b}$. When film stiffness is far greater than that of rubber, and film damping is far greater than that of rubber, water film stiffness and rubber damping can be neglected. Thus, $k_{b}$ and $c_{b}$ can be simplified as follows.

$$
\begin{aligned}
k_{b} & \approx \frac{2 L R \sin \left(\theta_{t} / 2\right) E}{s}, \\
c_{b} & \approx(1-\delta) \frac{\mu L C_{f}}{\Psi^{3}} .
\end{aligned}
$$

According to the above equations, stiffness of waterlubricated rubber bearings mainly depends on rubber stiffness while bearing damping is determined by water film 


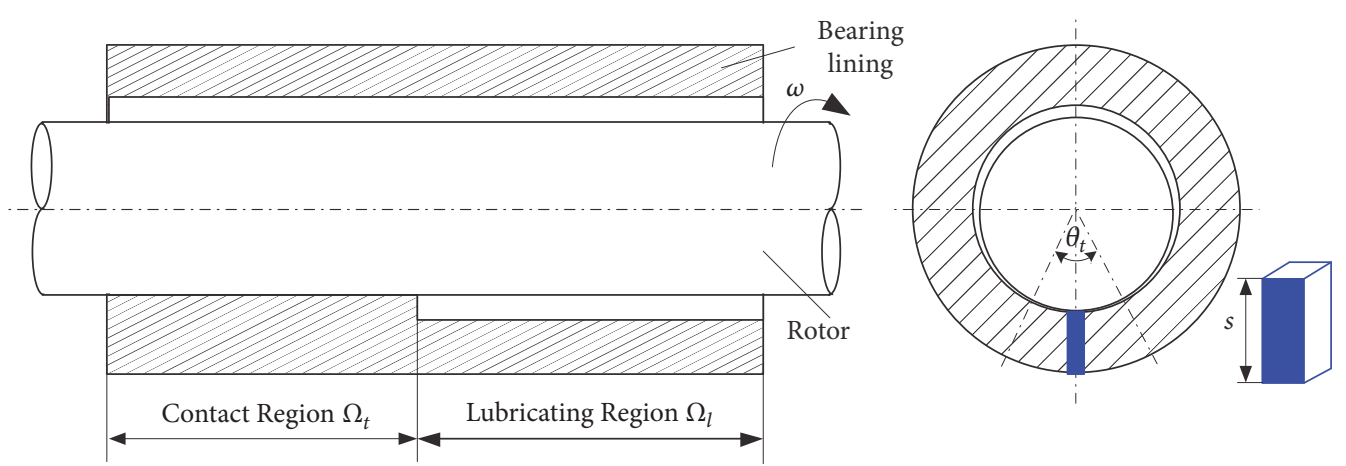

FIGURE 13: Zoning map of mixed lubricating bearings.

damping. The less contact length ratio is, the larger bearing damping becomes. The above statement is only a simplified consideration of mixed lubricated bearings, and more complete model and experiments will be the focus of future research.

\section{Conclusions}

Aiming at dynamic characteristic experimental study of water-lubricated rubber bearings in mixed lubrication, researches are carried out on test rig and identification method and rules of dynamic characteristic in different conditions are proposed in this paper. Conclusions are as follows:

(1) When rotational speed is less than $700 \mathrm{r} / \mathrm{min}$, even if specific pressure is $0.05 \mathrm{MPa}$, it is difficult to form completely water film lubrication on the rubber bearing which was investigated, and rub and impact of the shaft and bearing are obvious.

(2) In this paper, an identification method of dynamic characteristic coefficients based on rotor self-excited is proposed, and it provides a new idea for the dynamic performance test of bearing in mixed lubrication. It also has the application prospect in field unit. For example, sensor dynamic load can be installed on the back of bearings, and joint vibration data can identify dynamic characteristic coefficients of bearings.

(3) In mixed lubrication, the water film, rubber, and contact jointly determine dynamic characteristics of water-lubricated rubber bearings. The contact condition has a significant effect on the bearing stiffness, and water film friction damping has a significant effect on bearing damping. As for the particular investigated bearing, when rotational speed is in the range of $400 \sim 700 \mathrm{r} / \mathrm{min}$ and specific pressure is in the range of $0.03 \sim 0.07 \mathrm{MPa}$, bearing stiffness is in the range of $5.6 \sim 10.06 \mathrm{~N} / \mu \mathrm{m}$ and bearing damping is in the range of $1.25 \sim 2.02 \mathrm{Ns} / \mu \mathrm{m}$.

\section{Nomenclature}

$d: \quad$ Shaft diameter $(\mathrm{mm})$

$D_{1}$ : Inner diameter $(\mathrm{mm})$

$R:$ Inner radius $(\mathrm{mm}), D_{1} / 2$

$D_{2}$ : Outer diameter $(\mathrm{mm})$

$L: \quad$ Bearing length $(\mathrm{m})$

$i$ : Number of two segments of bearings: 1 is the near motor part and 2 is far motor part

$F_{d i}:$ Self-excited force $(\mathrm{N})$

$m_{1 i}$ : Vibration quality $(\mathrm{kg})$

$Y_{d i}$ : Displacement of shaft relative to bearing (m)

$k_{b}$ : Bearing stiffness $(\mathrm{N} / \mu \mathrm{m})$

$k_{t}$ : Contact region stiffness $(\mathrm{N} / \mu \mathrm{m})$

$k_{l}$ : Lubricating region stiffness $(\mathrm{N} / \mu \mathrm{m})$

$c_{b}: \quad$ Bearing damping $(\mathrm{N} \cdot \mathrm{s} / \mu \mathrm{m})$

$c_{t}$ : Contact region damping $(\mathrm{N} \cdot \mathrm{s} / \mu \mathrm{m})$

$c_{l}$ : Lubricating region damping $(\mathrm{N} \cdot \mathrm{s} / \mu \mathrm{m})$

$k_{b i}$ : Stiffness coefficients of one bearing part $(\mathrm{N} / \mu \mathrm{m})$

$c_{b i}$ : Damping coefficients of one bearing part $(\mathrm{N} \cdot \mathrm{s} / \mu \mathrm{m})$

$k_{0 i}$ : Connection stiffness of shaft $(\mathrm{N} / \mu \mathrm{m})$

$k_{y i}$ : Hydraulic oil stiffness $(\mathrm{N} / \mu \mathrm{m})$

$k_{g i}$ : Transition stiffness between hydraulic pole and shaft $(\mathrm{N} / \mu \mathrm{m})$

$\omega$ : Vibration frequency $(\mathrm{Hz})$

$l_{t}$ : Contact region length $(\mathrm{m})$

$l_{l}$ : Lubricating region length $(\mathrm{m})$

$\theta_{t}$ : Contact angle $\left(^{\circ}\right)$

$\delta$ : Contact length ratio, $\delta=l_{t} / L$

$E$ : Compression modulus, $\mathrm{Pa}$

$C_{f}$ : Normalized vertical stiffness of water film $(\mathrm{N} \cdot \mathrm{s} / \mu \mathrm{m})$

$\Psi: \quad$ Clearance ratio

$\mu$ : Dynamic viscosity of water (Pa.s).

\section{Conflicts of Interest}

The authors declare that there are no conflicts of interest regarding the publication of this paper, and the funding in 
Acknowledgments will not lead to any conflicts of interest regarding the publication of this manuscript.

\section{Acknowledgments}

This paper is supported by projects from Key Lab of Marine Power Engineering and Tech authorized by MOT (KLMPET2016-02), the Fundamental Research Funds for the General Universities (WUT: 2016III023), and the National Natural Science Foundation of China (no. 51609191).

\section{References}

[1] L. Wojciech, "Experimental research on water lubricated three layer sliding bearing with lubrication grooves in the upper part of the bush and its comparison with a rubber bearing," Tribology International, vol. 82, pp. 153-161, 2015.

[2] C. L. Dong, L. Shi, L. Li, X. Bai, C. Yuan, and Y. Tian, "Stick-slip behaviours of water lubrication polymer materials under low speed conditions," Tribology International, vol. 106, pp. 55-61, 2017.

[3] K. P. Lijesh and H. Hirani, "Stiffness and damping coefficients for rubber mounted hybrid bearing," Lubrication Science, vol. 26, no. 5, pp. 301-314, 2014.

[4] T. W. Dimond, P. N. Sheth, P. E. Allaire, and M. He, "Identification methods and test results for tilting pad and fixed geometry journal bearing dynamic coefficients-a review," Shock and Vibration, vol. 16, no. 1, pp. 13-43, 2009.

[5] B. C. Majumdar, R. Pai, and D. J. Hargreaves, "Analysis of water-lubricated journal bearings with multiple axial grooves," Proceedings of the Institution of Mechanical Engineers, Part J: Journal of Engineering Tribology, vol. 218, no. 2, pp. 135-146, 2004.

[6] X. L. Zhang, Z. W. Yin, G. Y. Gao, and Z. Li, "Determination of stiffness coefficients of hydrodynamic water-lubricated plain journal bearings," Tribology International, vol. 85, pp. 37-47, 2015.

[7] A. Delgado, G. Vannini, B. Ertas, M. Drexel, and L. Naldi, "Identification and prediction of force coefficients in a five-pad and four-pad tilting pad bearing for load-on-pad and loadbetween-pad configurations," Journal of Engineering for Gas Turbines and Power, vol. 133, no. 9, Article ID 092503, 2011.

[8] A. M. Al-Ghasem and D. W. Childs, "Rotordynamic coefficients measurements versus predictions for a high-speed flexure-pivot tilting-pad bearing (load-between-pad configuration)," Journal of Engineering for Gas Turbines and Power, vol. 128, no. 4, pp. 896-906, 2006.

[9] L. Wang, Y. Fu, S. Pei, and H. Xu, “Theoretical and Experimental Study on the Axial Oil Film Stiffness of Tilting Pad Thrust Bearings," Tribology Transactions, vol. 60, no. 3, pp. 419-427, 2017.

[10] Z. L. Qiu and A. K. Tieu, "Identification of sixteen force coefficients of two journal bearings from impulse responses," Wear, vol. 212, no. 2, pp. 206-212, 1997.

[11] D. W. Parkins, "Measurement of Oil Film Journal Bearing Damping Coefficients-An Extension of the Selected Orbit Technique," Journal of Tribology, vol. 117, no. 4, p. 696, 1995.

[12] D. S. K. Reddy, S. Swarnamani, and B. S. Prabhu, "Experimental investigation on the performance characteristics of tilting pad journal bearings for small L/D ratios," Wear, vol. 212, no. 1, pp. 33-40, 1997.
[13] L. Wang, X. Z. Xiong, and H. Xu, "Dynamic Coefficients Identification of Water-Lubricated Hybrid Bearings Used in High-Speed Spindles with Different Excitation Methods," Shock and Vibration, vol. 2017, Article ID 2597910, 2017.

[14] W. Ouyang, L. Peng, R. Chen, and X. Yuan, "Simulated identification on dynamic characteristics of large heavy-load bearing," Journal of Vibroengineering, vol. 19, no. 5, pp. 3230-3242, 2017.

[15] R. F. Salant and A. L. Flaherty, "Elastohydrodynamic analysis of reverse pumping in rotary lip seals with microasperities," Journal of Tribology, vol. 117, no. 1, pp. 53-59, 1995.

[16] J. T. Xing, Z. Tian, and X. P. Yan, "The dynamics of ship propulsion unit-large hull-water interactions," Ocean Engineering, vol. 124, pp. 349-362, 2016.

[17] Y. Han, C. Chan, Z. Wang et al., "Effects of Shaft Axial Motion and Misalignment on the Lubrication Performance of Journal Bearings Via a Fast Mixed EHL Computing Technology," Tribology Transactions, vol. 58, no. 2, pp. 247-259, 2015.

[18] T. A. Pafelias and C. A. Broniarek, "Bearing-system dynamic with general misalignment in the journal bearings," ASLE Transactions, vol. 24, no. 3, pp. 379-386, 1981.

[19] O. Ebrat, Z. P. Mourelatos, N. Vlahopoulos, and K. Vaidyanathan, "Calculation of journal bearing dynamic characteristics including journal misalignment and bearing structural deformation," Tribology Transactions, vol. 47, no. 1, pp. 94-102, 2004.

[20] W. Ouyang, R. Chen, L. Peng, X. Zhang, X. Yuan, and Q. Meng, "Main stiffness and main damping of sliding bearings considering local contact," Hsi-An Chiao Tung Ta Hsueh/Journal of Xian Jiaotong University, vol. 48, no. 1, pp. 112-117, 2014. 


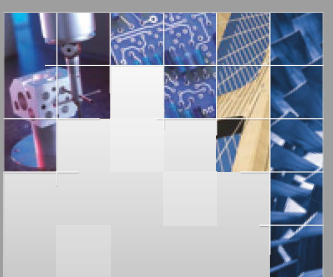

\section{Enfincering}
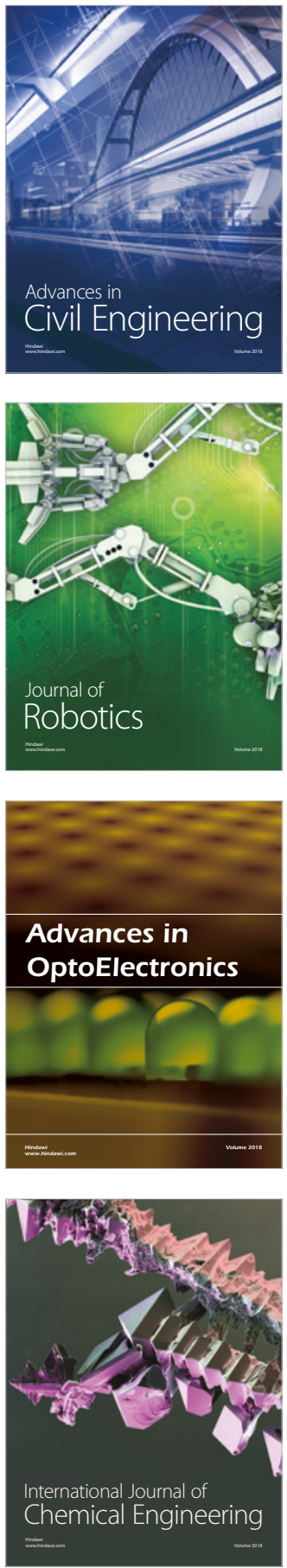

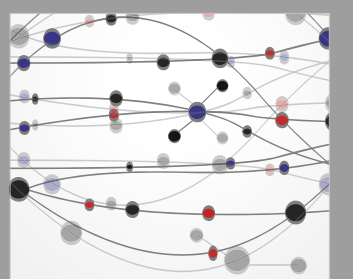

\section{Rotating \\ Machinery}

The Scientific World Journal

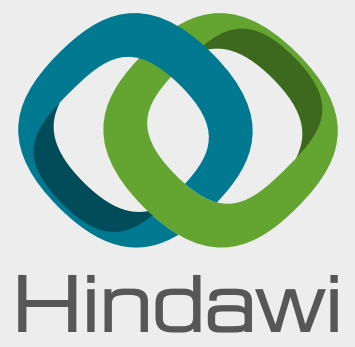

Submit your manuscripts at

www.hindawi.com
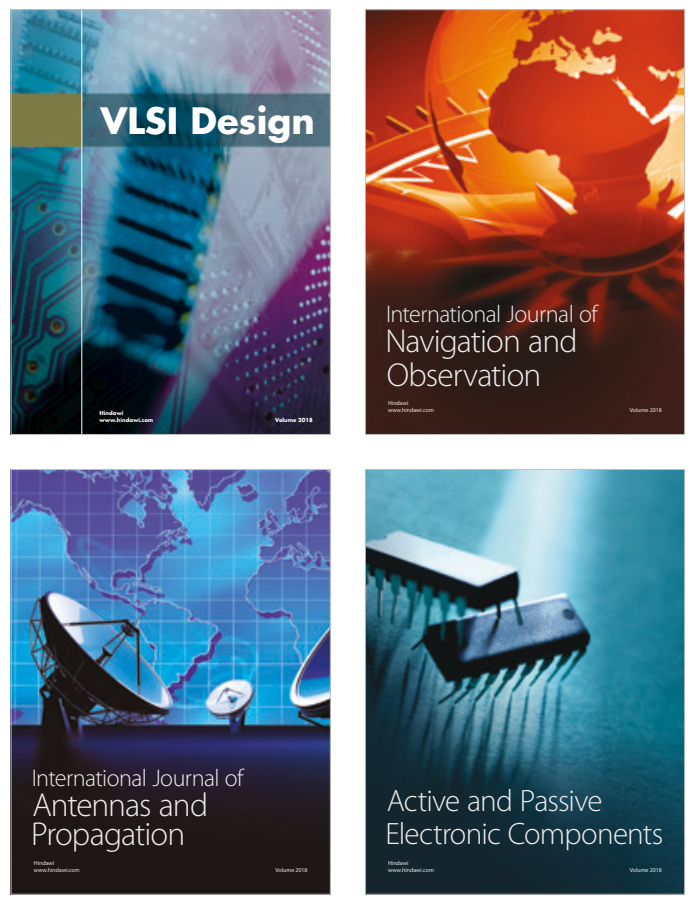
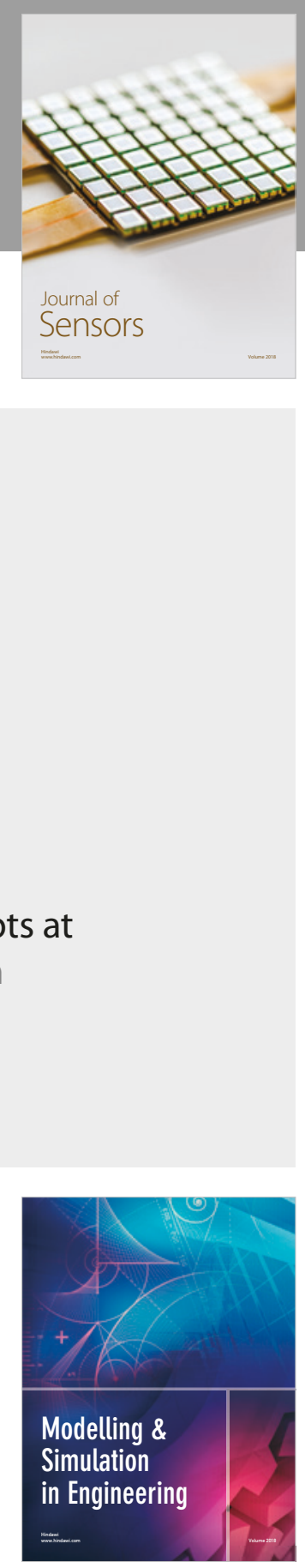

\section{Advances \\ Multimedia}
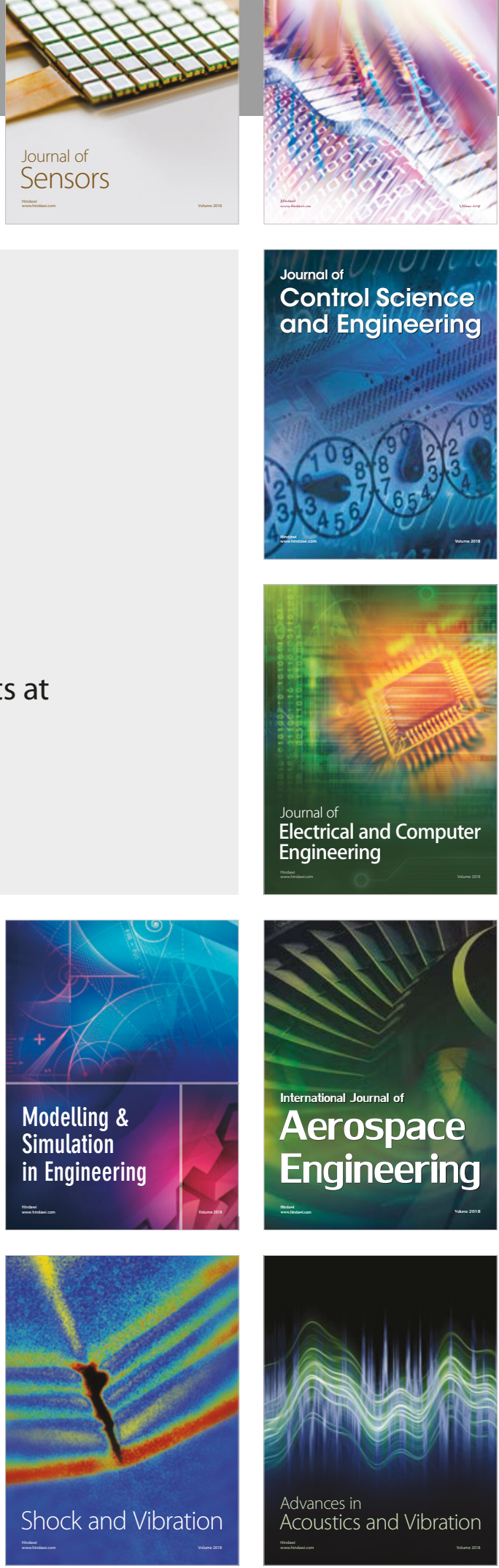